\title{
Diagonal chromatographic selection of cysteinyl peptides modified with benzoquinones
}

\author{
Loïc Dayon • Hubert H. Girault
}

Received: 20 May 2007 /Revised: 30 June 2007 / Accepted: 4 July 2007 /Published online: 16 August 2007

(C) Springer-Verlag 2007

\begin{abstract}
The derivatization of cysteine-containing peptides with benzoquinone compounds is rapid, quantitative and specific in acidic media. The conversion of cysteines into hydrophobic benzoquinone-adducted residues in peptides is used here to alter the chromatographic properties of cysteinyl peptides during liquid chromatography separation. The benzoquinone derivatization is shown to allow the accurate selection of cysteine-containing peptides of bovine serum albumin tryptic digest by diagonal reversed-phase chromatography, which consists of one primary and a series of secondary identical liquid chromatographic separations, before and after a cysteinyl-targeted modification of the peptides by benzoquinone compounds.
\end{abstract}

Keywords COFRADIC ${ }^{\mathrm{TM}} \cdot$ Labeling $\cdot$ Liquid chromatography $\cdot$ Mass spectrometry $\cdot$ Proteomics $\cdot$ Tagging

Electronic supplementary material The online version of this article (doi:10.1007/s00216-007-1492-8) contains supplementary material, which is available to authorized users.

\section{Dayon · H. H. Girault $(\bowtie)$}

Laboratoire d'Electrochimie Physique et Analytique,

Ecole Polytechnique Fédérale de Lausanne (EPFL),

Station 6,

1015 Lausanne, Switzerland

e-mail: hubert.girault@epfl.ch

Present address:

L. Dayon

Biomedical Proteomics Research Group,

Department of Structural Biology and Bioinformatics,

Faculty of Medicine, University of Geneva,

Geneva, Switzerland

\section{Introduction}

The identification and quantification of the proteins linked to stimuli is the basis of proteomics. Disease and regulatory events can, in this way, be recognized as the up- and downregulation of certain proteins. The modification of amino acids has been used extensively for the relative quantification of parallel cellular extracts. Isotopic tags, like the isotopecoded affinity tag (ICAT) [1], have enabled the relative quantification of proteins through mass spectrometry (MS). Nevertheless, specific modifications of amino acids are often performed for other reasons, namely the isolation of compounds of interest and the detection of characteristic features. These modification strategies, which aim at reducing sample complexity and simplifying the analysis of data, can be applied at the protein or at the proteolytic peptide level.

Originally, diagonal chromatography was based on a very simple observation. When a sample is chromatographed in the $x$ direction of a paper and dried, and then rechromatographed in the perpendicular $y$ direction using the same elution conditions, the analytes appear in a diagonal line on the 2-D chromatogram. Compounds that are chemically modified between the two runs such that their partition coefficients are affected will consequently move from the diagonal and be specifically recognized. In 1966, Brown and Hartley described such a technique for the isolation of cysteine peptides by diagonal paper electrophoresis, by exposing the paper to vapors of performic acid, converting cysteine to cysteic acid before the reseparation [2]. Similar procedures were employed later for the isolation of peptides carrying free amines [3], and methionine- [4], histidine- [5] and tyrosine-containing 
peptides [6]. Vandekerckhove and coworkers have recently applied the diagonal chromatography technique to highperformance liquid chromatography (HPLC) for the targeted proteomic isolation of analytes (reviews have been recently published $[7,8])$. Fractions collected from a first reversed-phase (RP) HPLC run are chemically treated and rechromatographed. The modified analytes then present a different retention time $\left(t_{\mathrm{R}}\right)$ during the second run. Methionine-containing peptides and cysteine-containing peptides were specifically isolated $[9,10]$. In the same way, Gevaert et al. demonstrated that this elegant method, so-called combined fractional diagonal chromatography (COFRADIC ${ }^{\mathrm{TM}}$ ), is able to reduce the complexity of proteomic samples while retaining essential identification information when targeting the N-terminal tryptic peptide of proteins [11]. Regnier and coworkers investigated the potential of the methods for the study of post-translational modifications by enzymatic removal of the phosphorylation modification before the second RP-HPLC [12]. This approach was further used to analyze the phosphoproteome of human HepG2 hepatocytes [13], and a procedure to map $\mathrm{N}$-glycosylation sites was presented [14].

The derivatization of cysteinyl peptides with 1,4-benzoquinone $(1,4-B Q)$ (Scheme 1) was carried out to study the specific fragmentation of benzoquinone-peptide adducts during electrospray ionization (ESI) MS [15] by a pattern recognition algorithm called SALSA (scoring algorithm for spectral analysis) [16]. Moreover, the reaction of some substituted 1,4-BQ compounds (noted BQ in general) with cysteine was shown to be rapid and selective for the thiol group of L-cysteine when performed in an acidic medium [17]. An evaluation of the use of $B Q$ for the modification and isolation of cysteine peptides by diagonal chromatography is proposed herein. The derivatization is easily performed between the first and second RP-HPLC runs, taking advantage of the fact that the derivatization reaction can be performed in acidic conditions. Substituted BQs, with increasing hydrophobicities, are evaluated in terms of

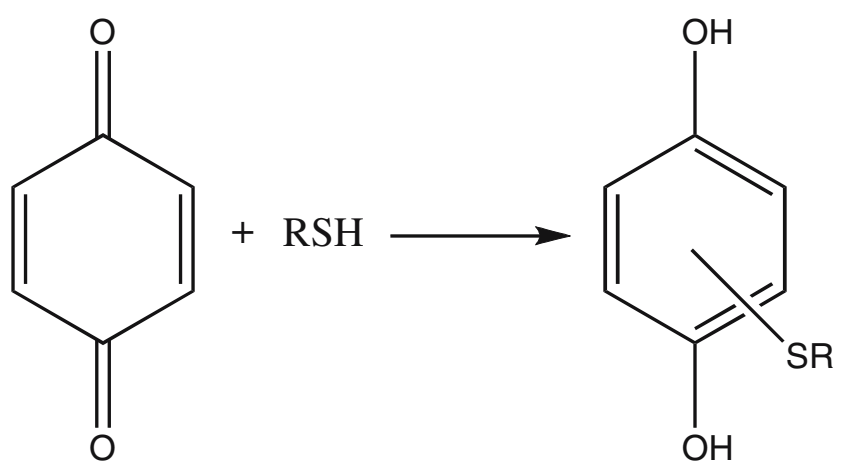

$1,4-B Q$

Scheme 1 Reaction of cysteine moieties (RSH) with 1,4-BQ their selectivity, their reactivity as well as the retention time shift they induce on targeted cysteinyl peptides. The cysteine modification with $1,4-\mathrm{BQ}$ compounds is then used for the diagonal reversed-phase chromatographic selection of the cysteinyl peptides of a bovine serum albumin (BSA) tryptic digest.

\section{Materials and methods}

\section{Chemicals}

1,4-Benzoquinone (1,4-BQ, $\geq 98 \%$ ), methyl-1,4-benzoquinone (Me-1,4-BQ, $\geq 98 \%$ ), 2,5-dimethyl-1,4-benzoquinone (2,5-diMe-1,4-BQ, $\geq 98 \%)$ and L-cysteine $(>99.5 \%)$ were from Fluka (Büchs, Switzerland). Synthetic peptide AIKCTKF $(>70 \%)$ was prepared by Catherine Servis at the Institut de Biochimie (Faculté de Médecine, Epalinges, Switzerland) and was further purified by semi-preparative RP-HPLC. Bovine serum albumin (BSA, minimum 98\%) and myoglobin from horse heart $(>90 \%)$ were purchased from Sigma (St. Louis, MO, USA). Sequencing grade modified trypsin was from Promega (Madison, WI, USA). Methanol ( $>99.8 \%$, Riedel-de Haën, Seelze, Germany), trifluoroacetic acid (TFA, 99\%, Merck, Darmstadt, Germany), formic acid (FA, 98-100\%, Merck) and acetic acid $(>99.5 \%$, Fluka) were used without any further purification. Water (UV-HPLC) and acetonitrile (HPLC-gradient grade) were bought from Panreac Quimica S.A. (Barcelona, Spain).

\section{Benzoquinone reagent evaluation}

The RP-HPLC separations were performed with an Alliance 2690 system from Waters (Milford, MA, USA) comprising a 996 photodiode array detector for ultraviolet (UV) detection.

To evaluate the potential of cysteinyl peptide derivatization via $\mathrm{BQ}$ tags in diagonal chromatography, the peptide AIKCTKF was first purified by semipreparative RP-HPLC. The peptide was collected and divided into two samples. The first sample was directly reinjected into the RP-HPLC. The second sample was modified with $\mathrm{BQ}$ through the addition of $1 \%(V / V)$ of BQ reagents at $100 \mathrm{mM}$ in $\mathrm{CH}_{3} \mathrm{CN}$ (large excess), where all of the BQs under study were found to be stable for at least one hour (data obtained from RP-HPLC survey not shown). The reaction was performed at room temperature for $60 \mathrm{~min}$. One hundred microliters of the modified mixture were rechromatographed. The unmodified and modified AIKCTKF were analyzed using the same Nucleosil 100-5 C18 column from Macherey-Nagel (Düren, Germany). The separation was run for $60 \mathrm{~min}$ using a gradient of $\mathrm{H}_{2} \mathrm{O} / \mathrm{TFA} 99.88 \% / 0.12 \%$ (solvent $\mathrm{A}$ ) and $\mathrm{CH}_{3} \mathrm{CN}$ (solvent $\mathrm{B}$ ). The gradient was run as follows: 
0-3 $\min 100 \% \mathrm{~A}$, then to $62 \% \mathrm{~A}$ and $38 \% \mathrm{~B}$ at $43 \mathrm{~min}$, $43 \% \mathrm{~A}$ and $57 \% \mathrm{~B}$ at $50 \mathrm{~min}$, and $20 \% \mathrm{~A}$ and $80 \% \mathrm{~B}$ at $60 \mathrm{~min}$ at a flow rate of $1 \mathrm{~mL} \mathrm{~min}{ }^{-1}$. Eluted compounds were collected and were analyzed by ESI-MS without further sample preparation using a Finnigan LCQ duo ion trap mass spectrometer (Thermo Electron, San José, CA, USA).

BSA digestion and isolation of proteolytic cysteinyl peptides by diagonal capillary LC ESI-MS

Two milligrams of BSA were dissolved in $2 \mathrm{~mL}$ of ammonium bicarbonate solution (5 mM, pH8). $1.23 \mathrm{mg}$ of DTT (to give a final concentration of $4 \mathrm{mM}$ ) and $20 \mu \mathrm{g}$ of trypsin (protein ratio of 1:100 w:w) were added. The digestion was run at $37^{\circ} \mathrm{C}$ for $4 \mathrm{~h}$. Five micrograms of the BSA digest were separated on an LC Packings Ultimate ${ }^{\mathrm{TM}}$ (Dionex, Olten, Switzerland) capillary RP-HPLC system equipped with a UV detector. An LC Packings C18 PepMap 100 column $(15 \mathrm{~cm}, 3 \mu \mathrm{m}, 100 \AA)$ was used. The separation was run for 60 min using a gradient of $\mathrm{H}_{2} \mathrm{O} /$ $\mathrm{CH}_{3} \mathrm{CN} / \mathrm{FA} 98 \% / 2 \% / 0.1 \%$ (solvent $\mathrm{C}$ ) and $\mathrm{H}_{2} \mathrm{O} / \mathrm{CH}_{3} \mathrm{CN} /$ FA $20 \% / 80 \% / 0.085 \%$ (solvent $\mathrm{D}$ ). The gradient was run as follows: $0-3 \min 100 \% \mathrm{C}$, then to $45 \% \mathrm{C}$ and $55 \% \mathrm{D}$ at $43 \mathrm{~min}, 30 \% \mathrm{C}$ and $70 \% \mathrm{D}$ at $50 \mathrm{~min}$, and $100 \% \mathrm{D}$ at $60 \mathrm{~min}$ at a flow rate of $4 \mu \mathrm{L} \min ^{-1}$. Fractions of $2 \mathrm{~min}$ each (i.e., $8 \mu \mathrm{L}$ ) were collected between 14 and $38 \mathrm{~min}$ of the gradient and pooled when separated by $12 \mathrm{~min}$. The pooled fractions of $16 \mu \mathrm{L}$ were treated by addition of $9 \mu \mathrm{L}$ of $\mathrm{BQ}$ at $14 \mathrm{mM}$ in $\mathrm{CH}_{3} \mathrm{CN}$ (final reaction mixture concentration of $\mathrm{BQ}$ of $5 \mathrm{mM}$ ), and the reaction was performed for $60 \mathrm{~min}$ at room temperature. The fractions were dried with a speed vacuum system (Martin Christ, Osterode am Harz, Germany) to get rid of $\mathrm{CH}_{3} \mathrm{CN}$, and then dissolved in $15 \mu \mathrm{L}$ of solvent $\mathrm{C}$. Ten microliters were injected and separated during an identical second LC run and analyzed on-line by ESI-MS (LCQ duo ion trap) with a sheath liquid of $1 \mu \mathrm{L} \mathrm{min}{ }^{-1}$ of solvent $\mathrm{D}$, a $\mathrm{N}_{2}$ sheath gas flow of 40 (arbitrary units), and a spray voltage of $4.5 \mathrm{kV}$. A classical ESI source was used. All mass spectra were acquired in positive ionization mode with a $\mathrm{m} / \mathrm{z}$ scan range of 500-2000 Th. The heated capillary was kept at $200{ }^{\circ} \mathrm{C}$. The ion transmission parameters were tuned automatically on a standard peptide. The mass accuracy was found to be between 200 and $300 \mathrm{ppm}$.

Protein identification

For each ESI-MS experiment, $m / z$ values were manually picked when the peaks showed good signal-to-noise ratios and their relative abundances were superior to $20 \%$ on the mass spectra. No tandem MS (MS/MS) experiments were performed because of license limitations that exclude extraction of the MS/MS data via SEQUEST. The obtained $m / z$ peak lists were converted to an $M$ peak lists, according to $M=(m / z) z-z m_{\mathrm{p}}$, where $m_{\mathrm{p}}$ is the mass of the proton (see the "Electronic supplementary material," Figure S1). The $M$ peak lists were then submitted to peptide mass fingerprinting (PMF) for identification of the protein using Aldente database search software (http://www.expasy.org/ tools/aldente/). The search was performed in UniProtKB/ Swiss-Prot and the main search parameters were Chordata for the taxonomy, monoisotopic for the resolution, $[\mathrm{M}]$ for the ion mode, and $0.4 \mathrm{Da}, 400 \mathrm{ppm}$ and $75 \mathrm{ppm}$
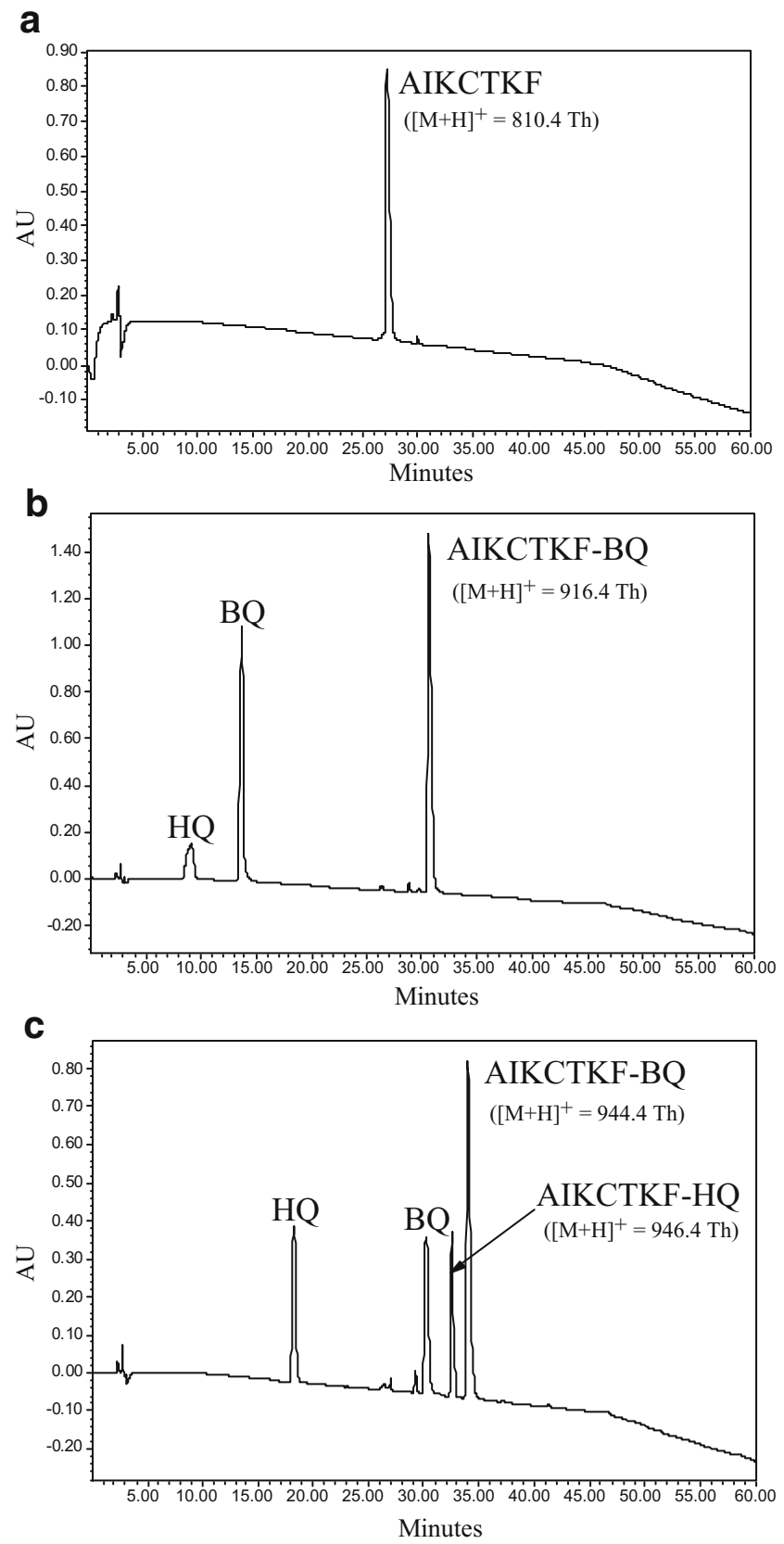

Fig. 1 Reversed-phase chromatograms at $214 \mathrm{~nm}$ of AIKCTKF (a), AIKCTKF modified with 1,4-BQ (b), and 2,5-diMe-1,4-BQ (c). The benzoquinone and hydroquinone compounds are labeled as BQ and HQ 
respectively for spectrometer shift, slop and internal error. Methionine oxidation was considered to be a variable modification, and the different $\mathrm{BQ}$ modifications were defined and set as fixed modifications. When several peaks presented a difference in mass that was lower than the spectrometer internal error, the mass values were replaced by their average.

\section{Results and discussion}

Evaluation of the use of benzoquinone reagents to alter the hydrophobic properties of a model peptide

The tagging of model peptides by BQ was carried out in order to modify their hydrophobicity properties. In order of increasing hydrophobicity, 1,4-benzoquinone (1,4-BQ), methyl-1,4-benzoquinone (Me-1,4-BQ), and 2,5-dimethyl1,4-benzoquinone (2,5-diMe-1,4-BQ) were employed to observe their influence (via chemical modification) on the peptide retention time $\left(t_{\mathrm{R}}\right)$.

The synthetic peptide AIKCTKF was chromatographed using a gradient of $60 \mathrm{~min}$ optimized for the separation of tryptic peptides (see "Materials and methods"). The eluted peptide was collected, treated with a BQ reagent and rechromatographed. The chromatograms obtained with and without derivatization are depicted in Fig. 1. The addition of the thiol onto Me-1,4-BQ has been previously shown to occur at different sites on the BQ core [17]. As a consequence, isobaric adducts were separated during LC and identified by ESI-MS. Me-1,4-BQ modification is thus not convenient when a separation step follows. When using 1,4-BQ as modifier, one product was quantitatively formed. Nevertheless, the adducted peptide was found to have a difference in mass of $2 \mathrm{Da}$ from the expected product (Fig. $1 \mathrm{~b}$ and Scheme 1). A control experiment involving the reaction of this labeled peptide with L-cysteine revealed that the addition of L-cysteine occurred on the labeled peptide (data not shown). This shows that the quinone tag bound to the peptide is in its oxidized form. As observed in a previous work [18], the large excess of BQ used during the labeling reaction induces the reoxidation of the hydroquinone (HQ) label. The BQ-modified peptide (which is $2 \mathrm{Da}$ lighter) is formed, as shown by the equilibrium in Scheme 2 [19]. The HQ formed in this reaction also appears in the chromatogram of Fig. 1b. When 2,5-diMe-1,4-BQ was used as the tagging reagent, most of the adducts obtained were the label-oxidized ones, although non-label-oxidized ones were also attained, as illustrated in Fig. 1c. The oxidation by the excess reagent is less efficient than with 1,4-BQ. The reaction was found to be total in terms of the labeling efficiency. Only trace amounts of the unmodified peptide can be seen on the chromatograms.

The unmodified AIKCTKF was detected at $t_{\mathrm{R} 1}=$ $27.2 \mathrm{~min}$. After modification, the major adduct formed came out at $t_{\mathrm{R} 2}=30.6 \mathrm{~min}$ and $34.0 \mathrm{~min}$ when modified with 1,4-BQ and 2,5-diMe-1,4-BQ, respectively. Due to its higher hydrophobicity, the $t_{\mathrm{R}}$ shift $\left(\Delta t_{\mathrm{R}}\right)$ is larger for the latter. Respective $\Delta t_{\mathrm{R}}$ values of 3.4 and $6.8 \mathrm{~min}$ show that the BQ tags can be potentially used for diagonal chromatography. Indeed, the minimum $\Delta t_{\mathrm{R}}$ of $3.4 \mathrm{~min}$ obtained with 1,4-BQ is theoretically sufficient for use with a sampling collection time of $1 \mathrm{~min}$ for the first dimension [12]. The fraction window from the first dimension of diagonal chromatography will be much wider and will show multiple analytes in the second RP-HPLC run. The modified peptides must have sufficient $\Delta t_{\mathrm{R}}$ values to move out from the overlap region so that they can be distinguished from false positives (i.e., peptides with shorter or longer retention times whose peak leading or trailing edges are collected in the fraction) moving out from the initial time interval. Studies with other model cysteinyl peptides were carried out and these confirmed the scale of the $t_{\mathrm{R}}$ shift induced by the BQ modification (data not shown).
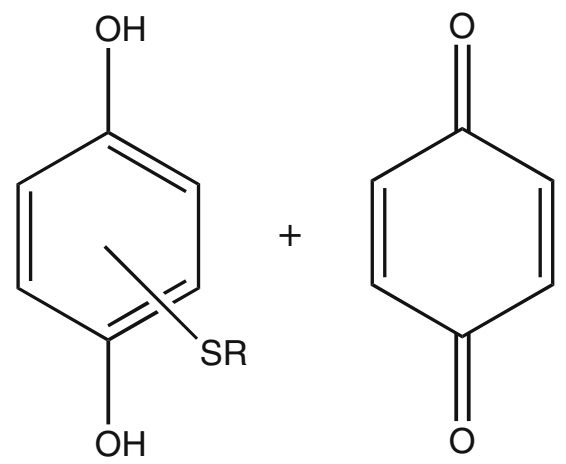

$1,4-B Q$
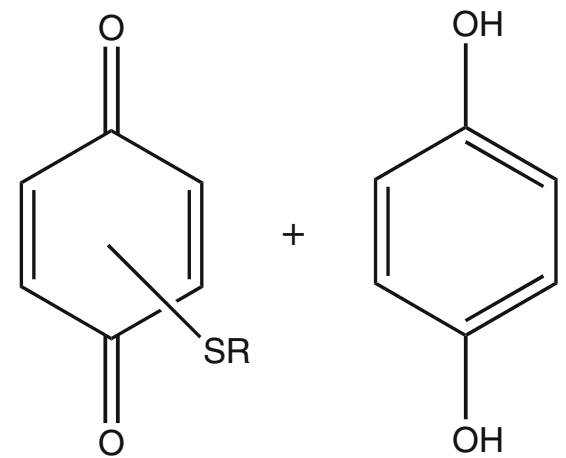

$1,4-\mathrm{HQ}$

Scheme 2 Excess 1,4-BQ induces reoxidation of the tagged product 
a
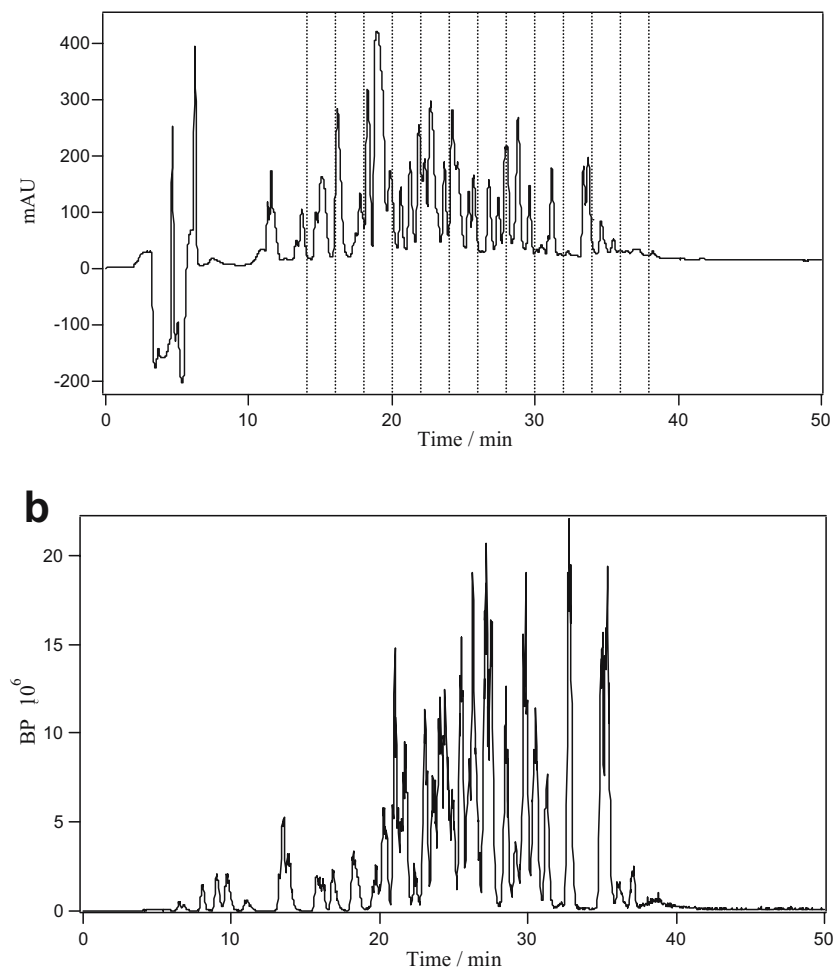

Fig. 2 Reversed-phase chromatogram at $214 \mathrm{~nm}$ of BSA digest (a) and a relative base peak chromatogram obtained by ESI-MS (b)

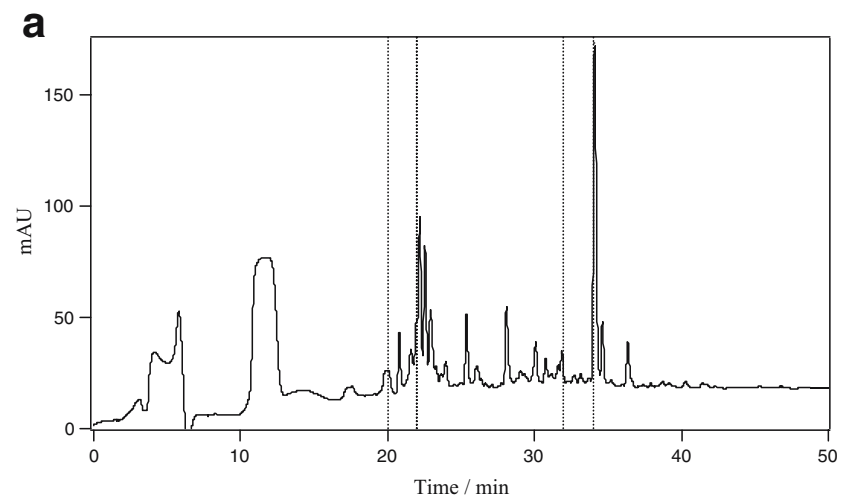

b

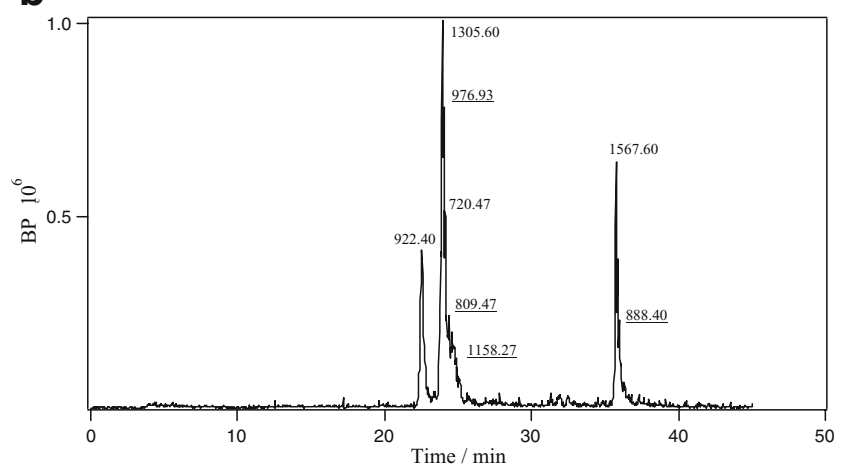

Fig. 3 Reversed-phase chromatogram at $214 \mathrm{~nm}$ of collected pooled fractions 4 and 10 of BSA tryptic peptides modified with 1,4-BQ (a) and a relative base peak chromatogram obtained by ESI-MS (b). The masses of identified modified cysteinyl peptides are underlined
Selection of the cysteinyl peptides from bovine serum albumin digest by diagonal liquid chromatography using 1,4-benzoquinone or 2,5-dimethyl-1,4-benzoquinone

The reaction between the peptides and the BQ compounds may vary when implemented on a mixture of peptides. A tryptic digest of BSA was tested in this diagonal chromatographic approach for the selection of cysteinyl peptides. BSA, which contains 35 cysteine residues and provides 25 cysteinyl peptides when digested by trypsin, is an excellent candidate for this proof of principle.

BSA digest was fractionated during a first capillary liquid chromatography dimension at a flow rate of $4 \mu \mathrm{L} \mathrm{min}{ }^{-1}$. Twelve fractions of 2 min (i.e., $8 \mu \mathrm{L}$ fractions) were collected as shown in Fig. 2. Fractions spaced by 12 min were combined and the six obtained fractions were derivatized by $\mathrm{BQ}$, either 1,4-BQ or 2,5-di-1,4-MeBQ. After the reaction, the fractions were dried under vacuum to get rid of $\mathrm{CH}_{3} \mathrm{CN}$. Each fraction was then rechromatographed using the same separation conditions, and analyzed on-line by ESI-MS. As illustrated by Figs. 3 and 4, some peptides move out from the initial fraction time window. MS analyses confirmed that the retention shifts of the peptides result from the reactions of their cysteine(s) with

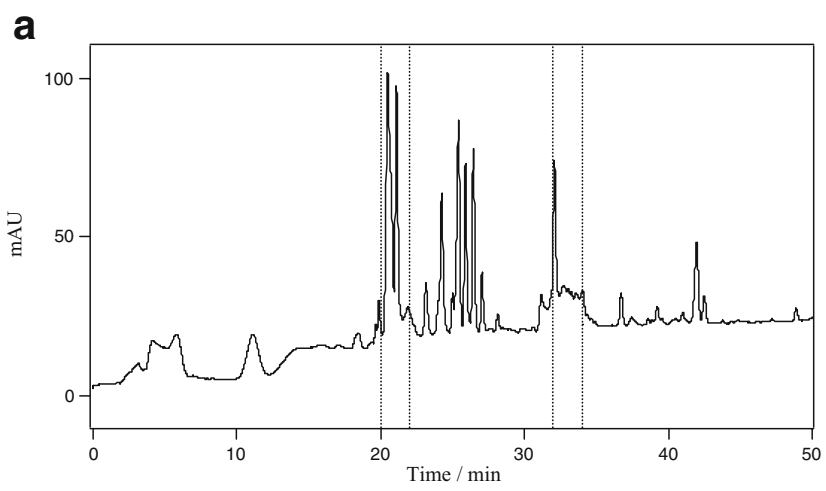

b

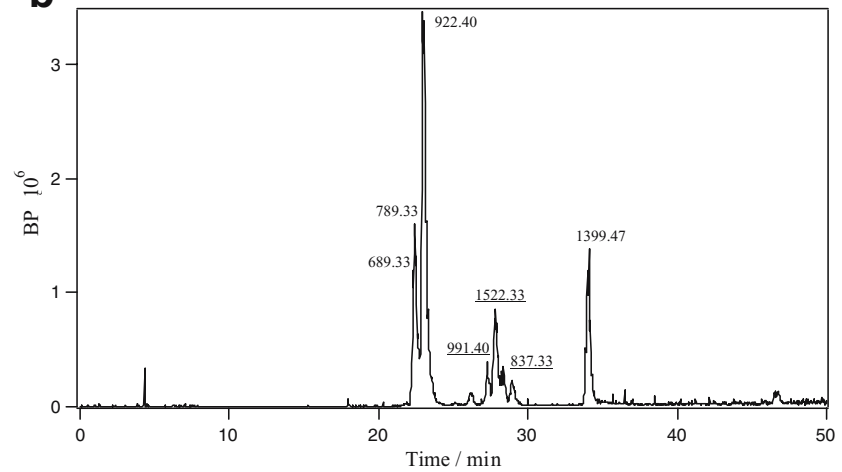

Fig. 4 Reversed-phase chromatogram at $214 \mathrm{~nm}$ of collected pooled fractions 4 and 10 of BSA tryptic peptides modified with 2,5-diMe-1, 4-BQ (a) and a relative base peak chromatogram obtained by ESI-MS (b). The masses of identified modified cysteinyl peptides are underlined 
hydrophobic BQ compounds (Table 1). The $m / z$ peak list, generated by the LC ESI ion trap MS analysis of the treated fractions, was converted to a $M$ peak list (see "Electronic supplementary material," Figure S1), and was submitted to peptide mass fingerprinting (PMF) to identify the protein using Aldente database search software (http://www.expasy. org/tools/aldente/). Using this software, it is possible to implement specific modifications, and a mass of 108 and $136 \mathrm{Da}$ (add $\mathrm{C}_{6} \mathrm{H}_{5} \mathrm{O}_{2}$, suppress $\mathrm{H}$ and add $\mathrm{C}_{8} \mathrm{H}_{9} \mathrm{O}_{2}$, suppress $\mathrm{H}$ were respectively specified in the Aldente

Table 1 Identification of BSA cysteinyl peptides by diagonal chromatography using 1,4-BQ and 2,5-diMe-1,4-BQ

\begin{tabular}{|c|c|c|c|c|c|c|}
\hline \multirow[t]{3}{*}{ Sequence (start-end) ${ }^{\mathrm{a}}$} & \multirow[t]{3}{*}{ Cysteine content } & \multirow{3}{*}{$\begin{array}{l}(m / z)^{\mathrm{b}} / \\
\mathrm{Th}\end{array}$} & \multicolumn{4}{|c|}{ Diagonal chromatography with $\mathrm{BQ}$ modification } \\
\hline & & & \multicolumn{2}{|l|}{$(m / z)^{\mathrm{b}} / \mathrm{Th}$} & \multicolumn{2}{|c|}{$\Delta t_{\mathrm{R}}{ }^{\mathrm{c}} / \min \left(\right.$ fraction $\left.^{\mathrm{d}}\right)$} \\
\hline & & & 1,4-BQ & $\begin{array}{l}\text { 2,5-diMe-1,4- } \\
\text { BQ }\end{array}$ & 1,4-BQ & $\begin{array}{l}\text { 2,5-diMe-1,4- } \\
\text { BQ }\end{array}$ \\
\hline TCVADESHAGCEK (76-88) & 2 & $\begin{array}{c}1349.60 \\
675.40\end{array}$ & - & $1621.53,811.53$ & - & $7.0(1)$ \\
\hline SHCIAEVEK (310-318) & 1 & $\begin{array}{c}1015.47 \\
508.40\end{array}$ & $\begin{array}{r}1123.40 \\
562.27\end{array}$ & 1151.40 & $3.6(1)$ & $4.4(1)$ \\
\hline QNCDQFEK (413-420) & 1 & 1011.47 & 1119.33 & 1147.33 & $2.7(2)$ & $5.0(2)$ \\
\hline LCVLHEK (483-489) & 1 & 841.47 & 949.40 & 977.40 & $2.4(2)$ & $4.4(2)$ \\
\hline NECFLSHK (123-130) & 1 & 977.53 & 1085.40 & 1113.33 & $1.9(2)$ & $4.2(2)$ \\
\hline ECCDKPLLEK (300-309) & 2 & $\begin{array}{r}1177.53 \\
589.47\end{array}$ & 1393.40 & - & $3.1(2)$ & - \\
\hline LKECCDKPLLEK (298-309) & 2 & $\begin{array}{r}1418.67 \\
710.00\end{array}$ & $1634.40,818.33$ & $\begin{array}{l}1690.47,845.93 \\
564.40\end{array}$ & $2.5(2)$ & $5.9(3)$ \\
\hline CCTESLVNR (499-507) & 2 & 1024.53 & & & & \\
\hline YICDNQDTISSK (286-297) & 1 & 1386.60 & 1494.47 & 1522.33 & $2.0(3)$ & $5.6(3 \& 4)$ \\
\hline GACLLPK (198-204) & 1 & 701.40 & 809.33 & 837.40 & $3.0(3 \& 4)$ & $5.9(4)$ \\
\hline NECFLSHKDDSPDLPK (123-138) & 1 & 1844.80 & $\begin{array}{c}1952.60 \\
976.93\end{array}$ & $1981.60,991.40$ & $1.5(4)$ & $3.3(4)$ \\
\hline CCADDKEACFAVEGPK (581-597) & 3 & $\begin{array}{r}1756.60 \\
879.00\end{array}$ & - & - & - & - \\
\hline EACFAVEGPK (588-597) & 1 & 1050.53 & 1158.27 & 1186.47 & $1.9(4)$ & $4.9(5)$ \\
\hline ETYGDMADCCEK (106-117) & 2 & 1364.47 & - & 1636.33 & - & $8.5(5)$ \\
\hline DDPHACYSTVFDK (387-399) & 1 & 1497.53 & $\begin{array}{c}1605.53 \\
803.33\end{array}$ & $1633.47,817.33$ & $1.9(5)$ & $4.4(5)$ \\
\hline ECCHGDLLECADDR (267-280) & 3 & - & 951.87 & $1986.60,993.80$ & $(5)$ & (5) \\
\hline EYEATLEECCAK (375-386) & 2 & 1388.60 & - & - & - & - \\
\hline $\begin{array}{l}\text { ECCHGDLLECADDRADLAK } \\
(267-285)\end{array}$ & 3 & 1039.07 & 1201.47 & 1243.40 & $2.5(5)$ & $7.2(5)$ \\
\hline RPCFSALTPDETYVPK (508-523) & 1 & 912.53 & $\begin{array}{r}1932.80 \\
966.93\end{array}$ & 980.87 & $1.0(6)$ & $2.5(6)$ \\
\hline LKPDPNTLCDEFK (139-151) & 1 & 1519.67 & 1627.47 & $1655.47,828.40$ & $1.5(6)$ & $4.1(6)$ \\
\hline YNGVFQECCQAEDK (184-197) & 2 & 1633.67 & 1849.53 & 1906.40 & $2.1(6)$ & $7.8(6)$ \\
\hline SLHTLFGDELCK (89-100) & 1 & $\begin{array}{r}1362.67 \\
681.93\end{array}$ & $\begin{array}{c}1470.53 \\
736.40\end{array}$ & $1498.47,749.27$ & $1.7(6 \& 7)$ & $2.7(7)$ \\
\hline LFTFHADICTLPDTEK (529-544) & 1 & $\begin{array}{r}1850.80 \\
926.07\end{array}$ & $\begin{array}{r}1957.53 \\
979.87\end{array}$ & $1986.60,994.47$ & $1.9(7)$ & $3.1(8)$ \\
\hline $\begin{array}{l}\text { DAIPENLPPLTADFAEDKDVCK } \\
(319-340)\end{array}$ & 1 & 1201.67 & 1255.47 & 1269.47 & $0.4(8)$ & $1.7(8)$ \\
\hline QEPERNECFLSHK (118-130) & 1 & 1616.53 & - & - & - & - \\
\hline MPCTEDYLSLILNR (469-482) & 1 & $\begin{array}{r}1667.80 \\
834.53\end{array}$ & $\begin{array}{r}1775.63 \\
888.40\end{array}$ & $1803.54,902.40$ & $0.2(10)$ & $1.8(11)$ \\
\hline
\end{tabular}

A reference one-dimensional LC ESI-MS experiment was carried out to compare the identified peptide masses with those obtained after derivatization with $\mathrm{BQ}$, and to determine the $\Delta t_{\mathrm{R}}$ induced by the modification.

${ }^{\mathrm{a}}$ Sequence of cysteinyl identified peptides. ${ }^{\mathrm{b}} \mathrm{m} / \mathrm{z}$ of identified cysteinyl peptides. ${ }^{\mathrm{c}} \Delta t_{\mathrm{R}}$ obtained from a reference one-dimensional LC ESI-MS experiment; $\Delta t_{\mathrm{R}}$ were corrected according to the experimental $t_{\mathrm{R}}$ values of non-cysteinyl peptides, which should maintain their retention times between chromatographic runs. ${ }^{\mathrm{d}}$ Fraction in which the peptide was found. 
modification frame) was added to the cysteine residues, corresponding respectively to $1,4-\mathrm{BQ}$ and 2,5-diMe-1,4-BQ addition. The robustness of the protocol in terms of the chemical reactivity of the tagging was assessed. Identical lists of matched peptide masses we obtained from the BSA identification whether the cysteine modification was defined as fixed or as variable. It can be concluded that the BQ modification is therefore fixed, quantitative and specific, because non-cysteinyl peptides retained their masses as well as their $t_{\mathrm{R}}$ values. As displayed in the chromatograms in Figs. 3 and 4 and in Figs. S2-S5 (see "Electronic supplementary material"), only the cysteine-containing peptides present significant retention time shifts. Moreover, no significant reoxidation of the adducted peptides by the excess BQ was observed. When fixed mass additions of 106 and $134 \mathrm{Da}$ (reoxidized labels) were implemented for 1,4-BQ and 2,5-diMe-1,4-BQ modifications, the PMF suggested only one and five peptides containing cysteine, respectively, whereas 20 and 21 were indicated when the reoxidation was ignored (Table 1). Verification of the mass spectral data indicated that the peptides undergoing reoxidation of the attached HQ are low-intensity $(1 / 3$ of their unoxidized counterparts). Reducing the excess of BQ for labeling or adding HQ after BQ labeling to reverse the equilibrium depicted in Scheme 2 (data not shown) are possible ways of avoiding uncontrolled reoxidation.

As a control, the same BSA digest was directly subjected to LC ESI-MS. The BSA identification score and protein coverage obtained with Aldente were similar to the ones obtained from the diagonal chromatographic experiments (scores of 1334, 1065 and 1015 and coverages of 74, 67 and $68 \%$, respectively, for the single-run analysis and for diagonal experiments with 1,4-BQ and 2,5-DiMe-1,4-BQ). Despite the decrease in the global MS signal for peptides present in two consecutive fractions and the loss of analytes when rechromatographing the fractions, the diagonal chromatographic technique presents many advantages. Interestingly, several cysteinyl peptides that were not identified in the LC ESI-MS analysis were recovered when the diagonal approach was used (Table 1). As a fraction undergoes an alteration of its cysteinyl peptides, its chromatographic time window enlarges during the second LC run. Coeluted peptide overlaps and related signal suppression during ESI-MS can be avoided, especially since the increased hydrophobic properties of the peptides may help their ESI [20]. Another advantage is the increase in the number of MS/MS measurements that can be performed on the sample. Finally, because cysteine is a rare amino acid, the technique could be of great value when it is necessary to simplify complex peptide mixtures, since it focuses the analysis on cysteinyl peptides only and gains valuable information on the presence of cysteine in peptides for protein identification [21].
The 2-D representation shown in Fig. 5 is convenient for evaluating the efficiency of the diagonal chromatography experiment. $\log \left(t_{\mathrm{R} 2}\right)$ values of the identified and diagonally chromatographed peptides are given as a function of their

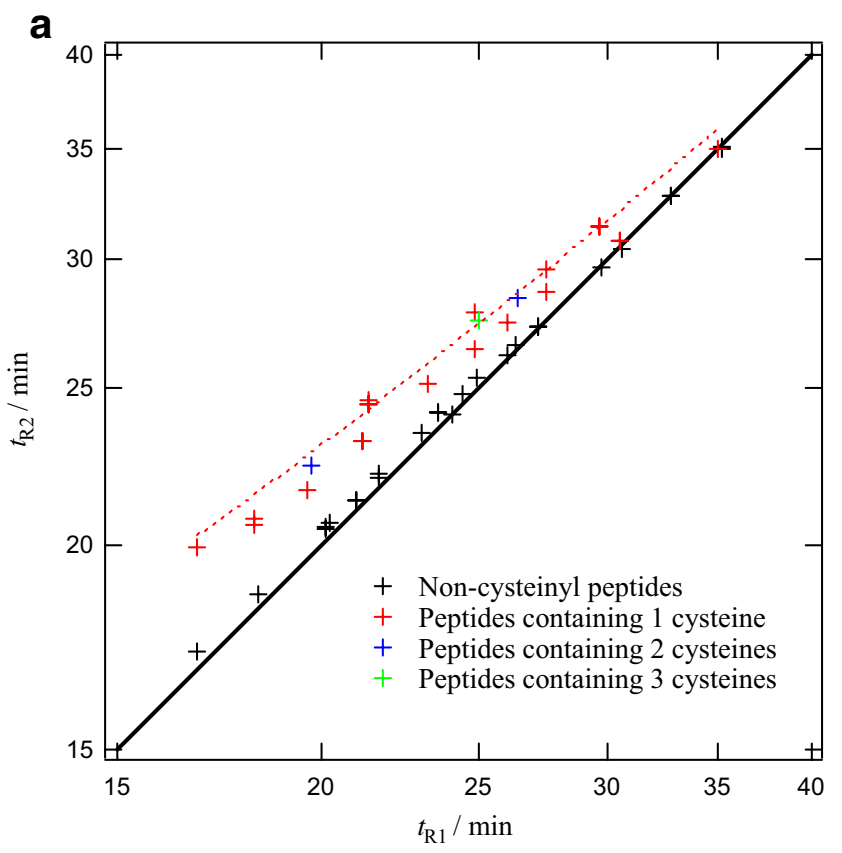

b

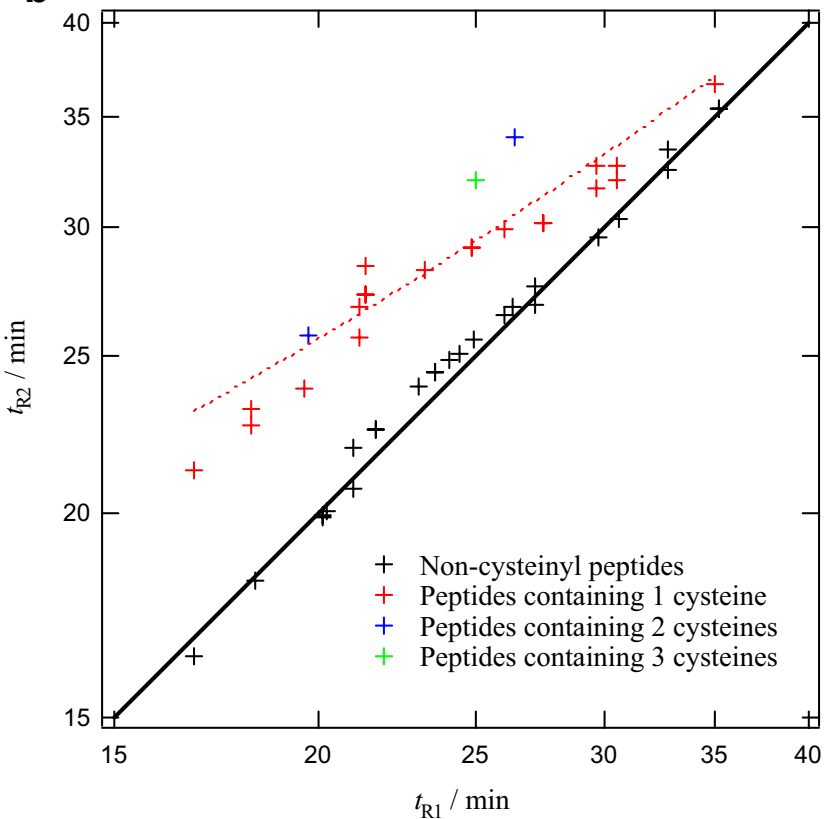

Fig. 5 2-D representations of the diagonal chromatographic separation of BSA tryptic peptides with 1,4-BQ (a) and 2,5-diMe-1,4-BQ (b). A log scale was employed to represent $t_{\mathrm{R} 2}$ as a function of $t_{\mathrm{R} 1}$. Cysteinyl peptides can be distinguished because the hydrophobic properties they acquire before the second RP-HPLC run make them shift from the diagonal. Peptides containing one, two and three cysteines appear in red, blue, and green, respectively. Non-cysteinyl peptides are represented in black. Trend lines are plotted for peptides containing one cysteine (discontinuous red lines) 
$\log \left(t_{\mathrm{R} 1}\right)$ values in the single-run LC ESI-MS experiment. Modified peptides are located above the diagonal as their Gibbs energies of partition from the aqueous solution to the hydrophobic stationary phase are larger, while unmodified peptides are positioned on it. As discussed previously, the retention shifts are larger for peptides modified with the most hydrophobic compounds, in the ranges of $0.2-3.6$ and 1.7-8.5 min for 1,4-BQ and 2,5-diMe-1,4-BQ, respectively (Table 1). 2,5-DiMe-1,4-BQ is therefore the most suitable tagging reagent for use in the selection of cysteinyl peptides by COFRADIC ${ }^{\mathrm{TM}}$. The $\Delta t_{\mathrm{R}}$ induced by the modification depends on the hydrophobicities and lengths of the peptides as well as the number of cysteines in their sequences. Assuming a linear relationship for Gibbs energy, as for the Kovats indices in gas chromatography for example, the Gibbs energy of partition for the modified peptide should obey the following equation:

$\Delta G_{\mathrm{p}}^{\mathrm{o}}\left(\mathrm{P}-\mathrm{T}_{n}\right)=\Delta G_{\mathrm{p}}^{\mathrm{o}}(\mathrm{P})+n \Delta G_{\mathrm{p}}^{\mathrm{o}}(\mathrm{T})$

where $\Delta G_{\mathrm{p}}^{\mathrm{o}}\left(\mathrm{P}-\mathrm{T}_{n}\right), \Delta G_{\mathrm{p}}^{\mathrm{o}}(\mathrm{P})$ and $\Delta G_{\mathrm{p}}^{\mathrm{o}}(\mathrm{T})$ represent the Gibbs energies of partition of the tagged peptide, the peptide, and the tag, respectively. This equation therefore predicts that $\Delta \ln \left(t_{\mathrm{R}}\right)$ should be proportional to the number of tags per peptide $n$. From Fig. 5 , it is clear that $\Delta \ln \left(t_{\mathrm{R}}\right)$ does not follow this prediction based on a direct Gibbs linear relationship. Indeed, the longer the peptide, i.e., the greater the retention time, the smaller the value of $\Delta \ln \left(t_{\mathrm{R}}\right)$. These data show that intramolecular hydrogen bonding and peptide folding for long peptides decrease the $\Delta \ln \left(t_{\mathrm{R}}\right)$ value and prevent the observation of a direct relationship between $\Delta \ln \left(t_{\mathrm{R}}\right)$ and the number of tags per peptide.

\section{Conclusion}

Diagonal chromatography is a convenient strategy for simplifying a complex protein mixture. By changing the alteration reaction, different classes of peptides can be differentiated and analyzed [7]. A simple method for the selection of cysteinyl peptides was developed based on cysteine modification with benzoquinone compounds. The derivatization protocol allows quantitative and selective processing in acidic media, and is perfectly adapted for handling between two RP-HPLC runs. It was demonstrated that the use of 2,5-dimethyl-1,4-benzoquinone provides sufficient retention time shifts (1.7-8.5 min depending on the hydrophobicity of the peptide and on its cysteine content). The diagonal chromatographic method presented herein has been shown to be efficient for the selection of the cysteinyl tryptic peptides of BSA, and would enable the simplification of tryptic samples as well as a reduction in the undersampling induced by the coelution of some peptides [22].

As a perspective, we have currently been investigating the potential of modifications of specific amino acids to shift the isoelectric point $(\mathrm{p} I)$ of peptides. The recently developed off-gel ${ }^{\mathrm{TM}}$ electrophoresis (OGE) fractionation technique could be used for this purpose [23, 24]. As OGE fractionates biomolecules in solution according to their $\mathrm{p} I$, the technique could easily be used for diagonal fractionation, on the condition that sufficient $\mathrm{p} I$ shifts can be induced on the targeted peptides [25].

Acknowledgement This work was supported by a Swiss National Science Fundation grant entitled "Development of new analytical tools for proteomics" (Grant No 200020-105489). The Ecole Polytechnique Fédérale de Lausanne is thanked for its financial support in the acquisition of the LC Packings UltimateTM system. Mélanie Abonnenc and Dr. Niels Lion are thanked for their expertise in LC ESI-MS and very fruitful discussions.

\section{References}

1. Gygi SP, Rist B, Gerber SA, Turecek F, Gelb MH, Aebersold R (1999) Nat Biotechnol 17:994-999

2. Brown JR, Hartley BS (1966) Biochem J 101:214-228

3. Butler PJG, Harris JI, Hartley BS, Leberman R (1967) Biochem J 103:P78-P79

4. Tang J, Hartley BS (1967) Biochem J 102:593-599

5. Cruickshank WH, Radhakrishnan TM, Kaplan H (1971) Can J Biochem 49:1225-1232

6. Cruickshank WH, Malchy BL, Kaplan H (1974) Can J Biochem 52:1013-1017

7. Gevaert K, Van Damme P, Ghesquiere B, Vandekerckhove J (2006) BBA-Proteins Proteomics 1764:1801-1810

8. Gevaert K, Van Damme P, Martens L, Vandekerckhove J (2005) Anal Biochem 345:18-29

9. Gevaert K, Ghesquiere B, Staes A, Martens L, Van Damme J, Thomas GR, Vandekerckhove J (2004) Proteomics 4:897-908

10. Gevaert K, Van Damme J, Goethals M, Thomas GR, Hoorelbeke B, Demol H, Martens L, Puype M, Staes A, Vandekerckhove J (2002) Mol Cell Proteomics 1:896-903

11. Gevaert K, Goethals M, Martens L, Van Damme J, Staes A, Thomas GR, Vandekerckhove J (2003) Nat Biotechnol 21:566569

12. Liu PR, Feasley CL, Regnier FE (2004) J Chromatogr A 1047:221-227

13. Gevaert K, Staes A, Van Damme J, De Groot S, Hugelier K, Demol H, Martens L, Goethals M, Vandekerckhove J (2005) Proteomics 5:3589-3599

14. Ghesquiere B, Van Damme J, Martens L, Vandekerckhove J, Gevaert K (2006) J Proteome Res 5:2438-2447

15. Mason DE, Liebler DC (2000) Chem Res Toxicol 13:976-982

16. Hansen BT, Jones JA, Mason DE, Liebler DC (2001) Anal Chem $73: 1676-1683$

17. Roussel C, Dayon L, Jensen H, Girault HH (2004) J Electroanal Chem 570:187-199

18. Dayon L, Abonnenc M, Prudent M, Lion N, Girault HH (2006) J Mass Spectrom 41:1484-1490 
19. Digga A, Gracheva S, Livingstone C, Davis J (2003) Electrochem Commun 5:732-736

20. Cech ND, Krone JR, Enke CG (2001) Anal Chem 73:208-213

21. Sechi S, Chait BT (1998) Anal Chem 70:5150-5158

22. Gevaert K, Pinxteren J, Demol H, Hugelier K, Staes A, Van Damme J, Martens L, Vandekerckhove J (2006) J Proteome Res 5:1415-1428
23. Horth P, Miller CA, Preckel T, Wenz C (2006) Mol Cell Proteomics 5:1968-1974

24. Michel PE, Crettaz D, Morier P, Heller M, Gallot D, Tissot JD, Reymond F, Rossier JS (2006) Electrophoresis 27:1169-1181

25. Xu CF, Wang HB, Li DM, Kong XP, Neubert TA (2007) Anal Chem 79:2007-2014 